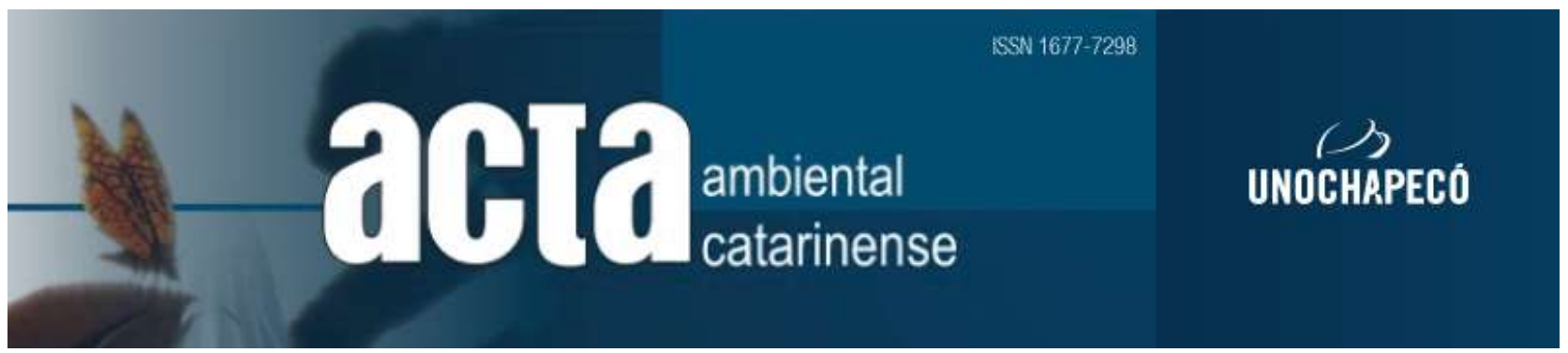

\title{
O Impacto da Ausência e a Presença Perniciosa: Covid-19 E A NECESSIDAdE dE REEDUCAÇÃo HuMANA PARA SOBREVIVÊNCIA DO MEIO AMBIENTE
}

\author{
Éderson Luís Silveira ${ }^{1}$ \\ Wilder Kléber Fernandes de Santana ${ }^{2}$
}

\begin{abstract}
Resumo
A preocupação com questões ambientais existe faz alguns séculos. Assim, inúmeras reflexões e eventos histórico-filosóficos voltados para a relação dos seres humanos com o ecossistema foram sendo legitimados com o passar do tempo e a intensificação dos efeitos nocivos das ações humanas sobre o meio também. Diante de tais considerações, este trabalho objetiva analisar a necessidade de reeducação humana para sobrevivência do meio ambiente diante dos impactos causados pela pandemia instaurada pelo COVID-19. Desse modo, este texto se inscreve no âmbito de escritos que visam promover o exercício da criticidade e da empatia. Em meio a uma pandemia que produziu um confinamento em larga escala de proporções globais se buscou pensar: qual o efeito da ausência humana e qual a responsabilidade das ações sobre o meio ambiente durante e depois de catástrofes naturais ou epidemiologias globais? Os resultados prévios apontam para a urgência de haver não apenas conscientização, mas a necessidade de que haja uma reeducação para a sensibilidade norteada a partir de questões alteritárias.
\end{abstract}

Palavras-chave: Meio ambiente, seres humanos, pandemia.

\begin{abstract}
Concern about environmental issues has existed for centuries. Thus, numerous reflections and historical-philosophical events focused on the relationship of human beings with the ecosystem were being legitimized over time and the intensification of the harmful effects of human actions on the environment as well. In view of these considerations, this work aims to analyze the need for human reeducation to survive the environment in view of the impacts caused by the pandemic established by COVID-19. Thus, this text is part of writings that aim to promote the exercise of criticality and empathy. In the midst of a pandemic that produced a large-scale confinement of global proportions, we sought to think: what is the effect of human absence and what is the responsibility of actions on the environment during and after global natural disasters or epidemiologies? Previous results point
\end{abstract}

\footnotetext{
${ }^{1}$ Doutorando e Mestre em Linguística pela Universidade Federal de Santa Catarina - UFSC.

${ }^{2}$ Doutorando e Mestre em Linguística pela Universidade Federal da Paraíba - UFPB
} 
to the urgency of not only awareness, but the need for a re-education for sensitivity guided by alteritary issues.

Keywords: Environment, human beings, pandemic.

\section{INTRODUÇÃ̃o}

A preocupação com o meio ambiente e a sustentabilidade remonta há séculos quando se viu a emergência de conter avanços da industrialização desregrada que surtia efeitos negativos sobre a natureza. $\mathrm{O}$ escritor estadunidense Henry David Thoreau (18171862), por exemplo, apregoava um retorno à vida em harmonia com a natureza. A polêmica da poluição por radiação emergiu após a Segunda Guerra Mundial e, em 1962, a cientista Rachel Carson (1907-1964) lançou a obra intitulada A primavera silenciosa. Entre os argumentos da obra está que a proteção do meio ambiente resulta em impactos diretos na saúde humana e foi realizado um alerta sobre uso de pesticidas químicos sintéticos. Em 1969 a humanidade teve acesso a primeira foto da Terra vista do espaço.

Desde a década de 1960, então, se viu a necessidade de buscar ações efetivas para proteção do meio ambiente em relação ao uso sustentável dos recursos do planeta. A necessidade de conscientização e preservação permanentes gerou, faz quase meio século, a sinalização quanto à importância de preservar o meio ambiente. Mas notou-se, desde cedo, que somente ressaltar a necessidade não é suficiente. Diante disso, da urgência de serem criadas políticas públicas voltadas para iniciativas de preservação, conscientização e tentativas de reversão de impactos no meio ambiente surge a grande conferência-marco na área de meio ambiente, em $1972^{3}$.

Em 1987 a Comissão Mundial sobre Meio Ambiente e Desenvolvimento gerou a publicação de um relatório intitulado Nosso Futuro Comum, que se tornou um marco por trazer o conceito de desenvolvimento sustentável para o âmbito do discurso político. Esta conferência ficou conhecida como Comissão Brundtland por causa de um dos principais nomes envolvidos, a médica Gro Harlem Brundtland, ex-Primeira Ministra da Noruega, que presidiu o evento. Foi a partir desse evento que se popularizou o uso da expressão "desenvolvimento sustentável". Pode ser lida, então, uma ${ }^{4}$ das definições do termo:

[...] desenvolvimento sustentável é aquele que atende às necessidades do presente sem comprometer a capacidade das gerações futuras de atenderem as suas próprias necessidades. Assume uma visão crítica ao modelo de desenvolvimento adotado pelos países industrializados e reproduzido pelas nações em desenvolvimento, ressaltando que o progresso econômico e social não pode se fundamentar na exploração

\footnotetext{
${ }^{3}$ Vale ressaltar, ainda, que no ano mencionado ocorreu a Conferência das Nações Unidas sobre o Meio Ambiente, em Estocolmo, na Suécia, tendo sido esta a primeira grande reunião de chefes de estado organizada pela Organização das Nações Unidas para este fim. No parágrafo 6 da Declaração da Conferência das Nações Unidas sobre o Meio Ambiente disponível em: << https://legal.un.org/avl/ha/dunche/dunche.html >> Acessado em 01 de maio de 2020 pode ser lido o seguinte "Chegamos a um ponto na História em que devemos moldar nossas ações em todo o mundo, com maior atenção para as consequências ambientais. Através da ignorância ou da indiferença podemos causar danos maciços e irreversíveis ao meio ambiente, do qual nossa vida e bem-estar dependem. Por outro lado, através do maior conhecimento e de ações mais sábias, podemos conquistar uma vida melhor para nós e para a posteridade, com um meio ambiente em sintonia com as necessidades e esperanças humanas...".

${ }^{4}$ Cabe assinalar que Scott (2002) é um autor que contabilizou acima de 300 definições para o conceito. A genericidade pode resultar em dificuldades de ações efetivas de implementação e viabilidade por causa da abrangência do termo. Assim, não é incomum que entre as críticas, esteja a de que a multiplicidade de definições pode dificultar a operacionalização do conceito.
} 
indiscriminada e devastadora da natureza (COMISSÃO MUNDIAL SOBRE MEIO AMBIENTE E DESENVOLVIMENTO, 1988, p. 46).

Ainda que seja bastante recente o surgimento da pandemia que ainda assola o planeta Terra é importante reconhecer que nosso trabalho se inscreve no hall de discussões que têm sido produtivas em relação ao tema que propõe problematizar como os estudos de Lucena, Holanda-Filho e Bomfim (2020), Netto (2020), Nunes (2020), Tostes e Melo Filho (2020) $)^{5}$ e Ventura et al (2020), por exemplo, intensificadas pela situação de emergência internacional relacionada à COVID-19, a qual foi declarada em 30 de janeiro de 2020 pela Organização Mundial da Saúde (OMS), conforme previsto no Regulamento Sanitário Internacional, uma Emergência de Saúde Pública de Importância Internacional - o mais alto nível de alerta da Organização. Em 11 de março de 2020 a COVID-19 foi caracterizada pela OMS como uma pandemia. Tal alerta promoveu posicionamentos por parte da comunidade científica global e, desde então, sua atenção tem se voltado para buscar soluções para combater a pandemia. Nosso trabalho, portanto, se constitui como um continuum a esses discursos já existentes que não apenas problematizam os efeitos causados pela instauração de uma pandemia, mas, sobretudo, a necessidade de que o humano reavalie suas práticas (de dominação) em relação ao meio ambiente.

Diante de tais considerações, este trabalho objetiva analisar a necessidade de reeducação humana para sobrevivência do meio ambiente diante dos impactos causados pela pandemia instaurada pelo COVID-19.

\footnotetext{
${ }^{5}$ Este é o primeiro livro brasileiro sobre os efeitos da pandemia do COVID-19. O livro conta com textos de pensadores de diversas partes do mundo como Noam Chomsky, Slavoj Zizek, o Nobel da economia Joseph Stiglitz e Boaventura de Sousa Santos, por exemplo, além de inúmeros pensadores nacionais.
}

Antes de prosseguir vale destacar que o coronavírus é de uma família de vírus que acomete animais e humanos. Nos seres humanos pode acarretar infecções respiratórias graves. $\mathrm{O}$ nome coronavírus se deve ao fato de que a imagem do vírus se assemelha a uma coroa (do espanhol coroa $=$ corona). Sua ocorrência foi relatada em dezembro de 2019 em Wuhan, China e, posteriormente, disseminou-se mundo afora. Os sintomas mais comuns são febre, tosse e dificuldade de respirar. No site da Organização Mundial da Saúde (World Health Organization $)^{6}$ pode ser lido acerca dos sintomas da doença:

Os sintomas mais comuns do COVID-19 são febre, tosse seca e cansaço. Outros sintomas que são menos comuns e podem afetar alguns pacientes incluem dores frequentes, congestão nasal, dor de cabeça, conjuntivite, dor de garganta, diarreia, perda de paladar ou cheiro ou erupção cutânea na pele ou descoloração dos dedos dos pés ou dos pés. Esses sintomas geralmente são leves e começam gradualmente. Algumas pessoas ficam infectadas, mas só têm sintomas muito leves. [...] Cerca de 1 em cada 5 pessoas fica gravemente doente e desenvolve dificuldade para respirar. Pessoas mais velhas e aqueles com problemas médicos subjacentes, como pressão alta, problemas cardíacos e pulmonares, diabetes ou câncer, têm maior risco de desenvolver doenças graves. No entanto, qualquer um pode pegar COVID-19 e ficar gravemente doente. Pessoas de todas as idades que experimentam febre

\footnotetext{
${ }^{6}$ Disponível em: $<<$ https://www.who.int/emergencies/diseases/novelcoronavirus-2019/question-and-answers-hub/q-adetail/q-a-coronaviruses\#: :text=symptoms $>>$ Acessado em 15 de junho de 2020.
} 


\begin{abstract}
e/ou tosse associadas à respiração/falta de ar, dor/pressão torácica ou perda de fala ou movimento devem procurar atendimento médico imediatamente. Se possível, recomenda-se ligar para o profissional de saúde ou unidade de saúde o quanto antes para que o paciente possa ser direcionado para a clínica certa (OMS, 2020, s. p., tradução nossa). .
\end{abstract}

Assim, o novo coronavírus (SARSCOV-2) causa a doença denominada COVID19 iniciada na China em dezembro de 2019. Numa entrevista à $\mathrm{BBC}^{7}$ o chefe da OMS, Tedros Adhanom Ghebreyesus, mencionou sobre a denominação do vírus: "Tivemos que encontrar um nome que não se referisse a uma localização geográfica, a um animal, a um indivíduo ou a grupo de pessoas, e que também seja pronunciável e relacionado à doença". Segundo o Ministério da Saúde as formas de transmissão ainda estão sendo estudadas/elucidadas, mas pode ser mencionado que a disseminação se dá via exposição a gotículas respiratórias ou de contato. Assim, qualquer pessoa que tenha tido contato cerca de um metro com alguém com sintomas respiratórios pode ter sido exposta. Entre a exposição e o aparecimento de sinais (ainda há o caso dos assintomáticos) pode haver um período de até duas semanas.

Em aspectos estruturais o manuscrito está dividido em duas seções. A primeira, intitulada Breves reflexões históricofilosóficas sobre a questão ambiental e o caso da COVID-19 realiza um breve percurso histórico de consolidação de políticas relacionada ao meio ambiente e adentra na atual problemática da pandemia instaurada pela COVID-19. A segunda seção, Processos

\footnotetext{
${ }^{7}$ Disponível em:

<<https://www.bbc.com/portuguese/internacional-

51469829>> Acessado em 02 de maio de 2020.

${ }^{8}$ Disponível em:

<<https://www.br.undp.org/content/brazil/pt/home/pos

t-2015.html > Acessado em 01 de maio de 2020.
}

de conscientização e atos humanos para restauração do meio ambiente, após fazer um levantamento filosófico-histórico da exploração animal e do meio ambiente, ressalta a emergência em que haja um processo conscientizador do humano para com a natureza.

\section{Material e Métodos}

\subsection{Breves reflexões histórico-filosóficas sobre a questão ambiental e o caso da COVID-19}

Em âmbito nacional foi em 1999, vinte e sete anos depois, que foi instituída a Política Nacional da Educação Ambiental no Brasil. Antes disso, ocorreu, em 1992, no Rio de Janeiro a Conferência das Nações Unidas sobre o Meio Ambiente e o Desenvolvimento (Rio 92). Em 2002 aconteceu em Johanesburgo, na África do Sul, a Rio+10 e, em 2012, no Rio de Janeiro, aconteceu a Conferência das Nações Unidas sobre Desenvolvimento Sustentável, a Rio+20.

Em setembro de 2015 na sede da ONU, em Nova York, ocorreu então a Cúpula de Desenvolvimento Sustentável. Foi aí que todas as nações da ONU definiram objetivos intitulados Objetivos de Desenvolvimento Sustentável ${ }^{8}$ - visando instaurar uma agenda de desenvolvimento sustentável articulada aos Objetivos do Milênio buscando impactar sustentavelmente o mundo todo. Finalmente, com foco de ano-limite o ano de 2030 a agenda ficou conhecida como Agenda 2030 para o Desenvolvimento Sustentável ${ }^{9}$.

Segundo Jacobi (2007, p. 55), apoiando-se em Beck (1997):

\footnotetext{
${ }^{9}$ Disponível em:

<<https://nacoesunidas.org/pos2015/>> Acessado em 01 de maio de 2020.
} 
A sociedade, produtora de riscos, se torna crescentemente reflexiva, o que significa dizer que ela se torna um tema e um problema para si própria. A sociedade se torna cada vez mais autocrítica e, ao mesmo tempo em que a humanidade põe a si em perigo, reconhece os riscos que produz e reage diante disso. A sociedade global "reflexiva" se vê obrigada a autoconfrontar-se com aquilo que criou, seja de positivo ou de negativo.

Essa questão da reflexividade se apresenta como uma forma de pensar nas consequências da ação humana sobre o meio em que vive. Mas, recentemente, algo mudou. Diz respeito à ação humana, mas não necessariamente sobre a presença humana. Diz respeito a uma proliferação de ausências que surtiu impactos significativos no mundo todo. Recentemente uma pandemia fez com que a maior parte da população mundial se resguardasse, reduzisse ou interditasse a abertura de lugares frequentados cotidianamente ou com relativa frequência.

Considerada até o momento (abril de 2020, enquanto este texto é redigido) ação efetiva mais eficaz a quarentena está fazendo com haja um aumento do consumo de serviços de entrega, o que aumenta o volume de resíduos recicláveis próximo a residências, mas, também, fez com que houvesse redução de resíduos em áreas públicas, como ruas, calçadas, praças e parques, por exemplo. Isso por causa da diminuição de automóveis nas ruas, menos lixo sendo jogando em rios e vias públicas e poucas fábricas emitindo poluentes - já que empresas que não produzem bens essenciais paralisaram ou reduziram atividades. Sobre a terminologia vale destacar, a partir de informações extraídas do site oficial do TELESSAÚDERS-UFRGS, que é um núcleo de pesquisa vinculado ao Programa de Pós-Graduação em Epidemiologia da Faculdade de Medicina da Universidade Federal do Rio Grande do Sul (UFRGS):
Distanciamento social é a diminuição de interação entre as pessoas de uma comunidade para diminuir a velocidade de transmissão do vírus. É uma estratégia importante quando há indivíduos já infectados, mas ainda assintomáticos ou oligossintomáticos, que não se sabem portadores da doença e não estão em isolamento. Esta medida deve ser aplicada especialmente em locais onde existe transmissão comunitária, como é o caso do Brasil, quando a ligação entre os casos já não pode ser rastreada e o isolamento das pessoas expostas é insuficiente para frear a transmissão.

[...]

Isolamento é uma medida que visa separar as pessoas doentes (sintomáticos respiratórios, casos suspeitos ou confirmados de infecção por coronavírus) das não doentes, para evitar a propagação do vírus. $\mathrm{O}$ isolamento pode ocorrer em domicílio ou em ambiente hospitalar, conforme o estado clínico da pessoa. [...] Essa ação pode ser prescrita por médico ou agente de vigilância epidemiológica e tem prazo máximo de 14 dias. $\mathrm{Na}$ prescrição do isolamento o paciente deve assinar um termo de consentimento livre e esclarecido [...] e seguir as orientações para evitar o contágio de seus contatos domiciliares.

Quarentena é a restrição de atividades ou separação de pessoas que foram presumivelmente expostas a uma doença contagiosa, mas que não estão doentes (porque não foram infectadas ou porque estão no período de incubação) (TELESSAÚDERS-UFRGS，2020, s. p., grifos do original)

Vale então mencionar o resultado do confinamento humano: desde o dia 15 de 
março de 2020 a Companhia Ambiental do Estado de São Paulo registrou, em todas as estações de monitoramento, diminuição da poluição da cidade em meio a quarentena; Nova York também teve diminuição da emissão de gases poluentes, houve redução de concentração de dióxido de nitrogênio $\left(\mathrm{NO}_{2}\right)$ em Wuhan, na China, epicentro da pandemia. Também houve diminuições consideráveis na poluição do norte da Itália, Madri e Barcelona. A cordilheira do Himalaia pode ser vista pela primeira vez em 30 anos em locais que ficam a $200 \mathrm{~km}$ de distância. Inúmeros animais selvagens também tiveram aparição em locais que os seres humanos deixaram de frequentar temporariamente neste momento em que cidades do mundo todo ficaram vazias por causa de um abandono forçado. Desde macacos nas proximidades do templo Prang Sam Yod no interior da Tailândia a pavões em Madri e javalis em Barcelona, ambas na Espanha.

A relação entre os lugares mencionados é que em todos eles foram implementadas medidas de confinamento, desde o início da quarentena. Se a presença humana no mundo gera descaso e aumento da degradação ambiental no planeta sua ausência tem se mostrado benéfica. Qual é a necessidade, então, de pensar na importância de uma ausência - não voluntária - para as discussões acerca do meio ambiente? $\mathrm{O}$ que esta ausência tem de tão importante que possa gerar problematizações acerca dos modos de olhar para o modo como os seres humanos impactam a vida na Terra?

\section{RESUltados E DisCUSSÃo}

\subsection{Processos de conscientização e atos humanos para restauração do meio ambiente}

Ser-nos-ia bastante exaustivo remontar um percurso sobre processos de conscientização humana sobre si e sobre o outro, o que não cabe para nossa delimitação investigativa. Partindo, então, de Kant, em sua Crítica da Razão Pura (2013), podemos dizer que suas asserções sobre o fenômeno da autoconsciência ganharam novos espaços no século $\mathrm{XX}$, de forma que o outro ganhou novos espaços e novas significações. Maciel, por exemplo, em sua obra Pensarlescrever o animal: ensaios de zoopoética e biopolítica compreende que, por meio de uma biopolítica direcionada para as interrelações entre o humano e meio ambiente, torna-se possível promover efeitos de conscientização humana diante da natureza e dos animais, enxergandoos como outros equipolentes, a quem devemos respeito.

A primeira seção do escrito de Maciel (2011), intitulado "O animal nas fronteiras do humano", agrega ensaios que reinserem em discussão filósofos e estudiosos da cultura que alçaram voz em conceitos sobre o ser "animal" e a possibilidade de definição do ser "homem", demarcados histórica e ideologicamente. É nesse direcionamento que se posiciona Benedito Nunes em $O$ animal e $O$ primitivo: os Outros de nossa cultura (2007), o qual considera que na história da dominação humana, o animal, o primitivo e a natureza assumem essa posição de inferioridade por serem vistos pela cultura dominante, desde o apogeu da Grécia antiga, como "bárbaros".

Essa barbárie civilizatória ganha raízes até os dias atuais (NUNES, 2007) e, nesse sentido, posicionamo-nos a favor de que é emergente um processo de reeducação humana para endossar a necessidade de equilíbrio ecológico e surtir efeitos na realidade ambiental. No entanto, não podemos perceber a natureza como um ser distante, isolado, mas, sobretudo "um lugar determinado e/ou percebido onde estão em relações dinâmicas e em constante interação" (REIGOTA, 2004, p. 21).

Um dos grandes esforços da filosofia moderna, por parte de Schopenhauer consiste na reconquista da proximidade perdida desde a Antiguidade mítica entre animal-humano e animal não humano. Ainda que ambos estejam 
sujeitos à dor e ao sofrimento, há um princípio distintivo: a racionalidade.

No bojo da literatura poética, por exemplo, validamos o pensamento de Rilke, que afirma, em sua Oitava Elegia, em Elegias de Duíno (RILKE, 1984, p. 36), que o animal vive no seio da natureza, "enquanto nós os trepidantes sofremos do mundo que nos punge e empobrece". De modo congruente, Clarice Lispector, no conto "O touro", em Laços de família (1988) simboliza o olhar animal como elementos vivos que possuem, encarnados, anseios e sentimentos frente à violência humana. Tanto na filosofia quanto na literatura, tais vozes de resistência também servem de alerta para enxergarmos que o animal não humano e a natureza continuam assumindo o papel outro extremado, aquele que é alienado da cultura antropocêntrica.

Acerca de rituais de exploração e maus tratos aos animais e à natureza em geral, corroboramos as assertivas de Singer (2008 [1975]), estudioso que problematiza o uso e a exploração dos animais não-humanos na indústria de experimentação, alimentação e entretenimento, o que dialoga com as vozes de Francione (2013 [1954]), defensor do "abolicionismo Animal". No horizonte do filósofo (2013 [1954], p. 27): “A razão da profunda inconsistência entre o que dizemos sobre os animais e como realmente os tratamos é o status, ou a condição, dos animais como nossa propriedade. Os animais são mercadorias que possuímos e cujo único valor é aquele que nós, como proprietários, escolhemos lhes dar".

As posições de enfrentamento e de resistência assumidas por Singer (2008 [1975]) contra a exploração animal representam um grande avanço no sentido dos Direitos Animais, que, por sua vez, têm fortalecido políticas públicas e garantia dos direitos animais no Brasil.

Se um ser sofre não pode haver qualquer justificativa moral para deixarmos de levar em conta esse sofrimento. Não importa a natureza do ser, o princípio da igualdade requer que seu sofrimento seja considerado em pé de igualdade com os sofrimentos semelhantes [...] $\mathrm{O}$ limite da senciência [...] é a única fronteira defensável de consideração dos interesses alheios. [...]. Os racistas violam o princípio da igualdade ao conferirem mais peso aos interesses de membros de sua própria raça quando há um conflito entre seus interesses e os daqueles que pertencem a outras raças. Os sexistas violam o princípio da igualdade ao favorecerem os interesses de seu próprio sexo. Analogamente, os especistas permitem que os interesses de sua própria espécie se sobreponham àqueles maiores de membros de outras espécies. O padrão é idêntico em todos os casos. (SINGER, 2008 [1975], p.10-11).

Das palavras antepostas, compreende o filósofo australiano que, da mesma maneira que existe uma recusa aos preconceitos de raça e sexo em relação à natureza e aos animais humanos, só se alcançará a verdadeira igualdade a partir da recusa ao preconceito especista, ou seja, à intolerância contra outras espécies que não sejam a humana.

Aspectos que nos redirecionem a práticas efetivas de reeducação ambiental devem ser valorados positivamente e postos em prática, uma vez que "Essas relações acarretam processos de criação cultural e tecnológica e processos históricos e políticos de transformação da natureza e da sociedade" (REIGOTA, 2004, p. 21). Na agenda de Pádua e Lago as partes integrativas da natureza

[...] não são compartimentos estanques, isolados entre si. No fundo, elas são diferentes facetas de uma mesma realidade e se complementam mutuamente: a Ecologia Natural nos ensina sobre o 
funcionamento da natureza, a Ecologia Social sobre a forma como as sociedades atuam sobre esse funcionamento, o Conservacionismo nos conduz à necessidade de proteger o meio natural como condição para a sobrevivência do homem, e o Ecologismo afirma que essa sobrevivência implica uma mudança nas bases da vida do homem na Terra". (PÁDUA; LAGO, 2004, p.16)

Isso significa que o humano pode iniciar seu processo de conscientização sobre si e sobre a natureza como outro a partir de ações alteritárias, no sentido de respeito ao seu espaço, e na mediação daquilo que se denomina exploração dos recursos naturais. Quando Pádua e Lago (2004) mencionam, por exemplo, que as matrizes ecológicas explicitam modos de funcionamento da natureza, é para que a enxerguemos como um organismo vivo, não como um ente a servir de satisfação humana.

Adentramos, então, ao pensamento de Laraia (2004), em seu livro Cultura: um conceito antropológico, em que se explana a necessidade de um refazer do comportamento humano. Sendo assim, é apenas em uma perspectiva de redirecionamento educativo que o humano é capaz de alcançar harmonia com na natureza, respeitado seus limites, compreendendo e não adentrando em seus espaços constitutivos.

Sobre o distanciamento social pode ser mencionado que não é algo inédito no reino animal. Não se trata de um conceito novo na natureza já que abelhas e chipanzés, por exemplo, se distanciam de seres da mesma espécie que estão doentes visando a não proliferação da doença entre os membros do grupo. Assim, não é incomum que várias espécies expulsem membros da comunidade quando estes estiverem infectados por algum patógeno. Tal mudança de comportamento se deve ao fato de que o instinto de sobrevivência faz repercutir em medidas que evitem o adoecimento. Pode ser mencionado que doenças bacterianas atingem abelhas atacando larvas de dentro para fora, como a cria pútrida americana, por exemplo. "É daí que o nome vem, a doença tem um aspecto pegajoso e marrom. Cheira muito mal", explica Alison McAfee, pós-doutoranda do departamento de Entomologia e Patologia Vegetal da Universidade Estadual da Carolina do Norte (NATIONAL GEOGRAFIC, 2020). Sobre o funcionamento da doença pode ser mencionado que:

[a]s larvas infectadas liberam certas substâncias químicas que as abelhas mais velhas conseguem detectar, como ácido oleico e $\beta$-ocimeno, um feromônio da abelha, de acordo com a pesquisa de McAfee. Uma vez identificados, as abelhas fisicamente removem esses membros doentes da colmeia, explica ela.

Como essa adaptação evolutiva protege a saúde da colônia, há décadas os apicultores e pesquisadores empregam técnicas de reprodução seletiva para esse comportamento. Essas abelhas mais "higiênicas" agora estão por toda a parte nos Estados Unidos (NATIONAL GEOGRAFIC, 2020, s. p.).

Ainda na matéria da National Geografic (2020) são mencionados os casos de outros animais que praticam o distanciamento de membros da mesma espécie como camundongos fêmeas que, ao farejar nos machos alguma infecção parasitárias urinária, se distanciam deles ou mesmo chipanzés, que afastam brutalmente os membros doentes da comunidade citando como fonte uma pesquisa da Universidade de Western Ontario.

Pensando no caso de confinamento humano, sabendo que não é único porque se repete no reino animal, há ainda uma diferença: os animais não sabem que se 
ficarem em casa poderão reduzir a taxa de transmissão. Os humanos sabem. A afirmação é de Joseph Kiesecker, cientista líder da The Nature Conservancy.

Trata-se, portanto, não de uma questão de instinto, mas de autoconscientização. Mas a não transmissão pode ser pensada no sentido de um cuidado consigo e com o outro, numa relação de causa e efeito na qual o comportamento de um influencia diretamente na saúde dos demais. Ações de negligência em relação a informações repassadas por órgãos oficiais de saúde, de aglomerações irresponsáveis em locais públicos sem medidas preventivas como distanciamento ou uso de máscaras também dizem respeito à forma como uma parcela da humanidade pensa sobre si e sobre os demais. Havendo ainda por parte dos seres humanos uma adesão parcial de medidas preventivas de disseminação e propagação da doença isso diz respeito não somente aos modos de viver em sociedade, mas a formas de pensar na sobrevivência. Então, a ausência dos seres humanos no planeta em locais que antes frequentavam, ao produzir diminuição dos níveis de poluição e reaparição de animais, por exemplo, pode ser um indicador sobre quanto a presença humana pode ser prejudicial.

Os grandes acidentes envolvendo usinas nucleares e contaminações tóxicas de grandes proporções, como os casos de Three-Mile Island (1979), Love Canal, Bhopal (1984) e Chernobyl (1986), e outros de menor porte, mas com impactos locais significativos, aumentam o debate público e científico sobre a questão dos riscos nas sociedades contemporâneas, o que converge com a questão da cidadania e da qualidade de vida. Isso decorre do fato de os problemas ambientais e os riscos decorrentes terem crescido a passos agigantados e de a sua lenta resolução ter se tornado de conhecimento público justamente pelo seu impacto (JACOBI, 2007, p. $55)$.

Precisamos cada vez mais de uma reeducação que leve à conscientização dos seres humanos, mas só a conscientização não basta. É necessário que haja uma reeducação para a sensibilidade. A educação do sensível perpassa uma questão central: não apenas educar para algo, mas para os efeitos daquilo para o qual se busca reeducar. Se algum problema é visto e negligenciado não estamos apenas no terreno da conscientização: a negligência é uma forma de agir a despeito de. Assim, sem reeducar para a sensibilização de sujeitos pode-se reduzir o ato de educar a mero exercício de transmissão de informações. Trata-se de repensar a lógica da experiência no sentido de vivenciar os acontecimentos deixando que atravessem formas de pensar, agir e sentir, deixando envolver-se, alteritariamente conforme bem sinalizou Duarte Júnior (2001).

A questão central, neste caso, não é necessariamente qual a informação que deve ser repassada, mas que ferramentas podem ser uteis no sentido de fazer frutificar a empatia em relação aos demais seres que habitam o planeta como um todo. Há, cada vez mais, uma necessidade urgente de que a sociedade produtora de riscos se torne reflexiva voltando-se, assim, para si mesma, em relação ao confronto com aquilo que ela mesma criou, positiva ou negativamente (JACOBI, 2007). Diferente do esperando no passado os avanços tecnológicos e científicos não levaram a humanidade ao desenvolvimento sustentável:

[O] debate internacional que teve início em Estocolmo e consolidou-se no Rio supera inexoravelmente a perspectiva tecnocrática no tratamento da crise ambiental, a ilusão ingênua de que os avanços do conhecimento científico seriam suficientes para permitir a emergência de um estilo sustentável de desenvolvimento. Os problemas 
ambientais são os problemas do desenvolvimento, de um desenvolvimento desigual para sociedades humanas e nocivo para os sistemas naturais (GUIMARÃES, 2001, p. 17).

Dessa forma, os riscos ambientais de graves consequências levam-nos a refletir sobre os limites das práticas sociais e a multiplicação ou agravamento para a emergência, enquanto seres que se voltam para si mesmos e para os efeitos do que fazemos em relação ao meio, do exercício da "reflexividade" (BECK, 1997). Diante disso cabe perguntar: que formas teremos de olhar para o mundo à nossa volta mediante e depois da pandemia em relação aos efeitos do que fazemos? Os padrões atuais de produção e de urbanização desenfreados continuam surtindo impactos consideráveis no ecossistema. A resposta virá com o tempo. Por hora o que temos são pistas de que do jeito que está não dá para continuar.

\section{CONSIDERAÇÕES FinAIS}

Para que se pudesse pensar em questões ambientais e de sustentabilidade foram historicamente desenvolvidos eventos mundiais, regionais e locais que visaram o aprendizado, a disseminação de informações e a conscientização dos seres humanos. A degradação desenfreada de recursos naturais, os impactos negativos e a exploração dos reinos animal e natural passaram a requerer que não apenas se pensasse em alternativas ecológicas de sobrevivência como também de frear impactos das práticas sociais.

Diante disso, este texto emerge no contexto de desenvolvimento de trabalhos que se voltam para a necessidade de uma reeducação humana pautada no exercício da criticidade, mas também de uma reeducação para a sensibilidade e para a empatia em relação ao meio. Por isso foram apresentados argumentos histórico-filosóficos que corroboram tal urgência. Como estamos vivendo diante de uma pandemia trata-se de um texto escrito no olho do furacão. Assim, ao voltar-se para si mesma, a sociedade precisa empreender esforços de reflexividade. Sem tal ação nem mesmo haverá lições suficientes porque tais lições só são apreendidas pelos que estão sensíveis á escuta do outro, que se colocam no lugar do outro.

Perante a negligência da degradação do meio ambiente deve existir a possibilidade de haver um engajamento entre diversos atores e sistemas de conhecimento a fim de que sejam capacitados profissionais numa perspectiva interdisciplinar educativa em todos os níveis dentro ou fora de instituições de pesquisa ou ensino. Além disso, é preciso pensar em ações fora das instituições formais para que a população em geral possa ser atendida na necessidade de desenvolvimento da criticidade e da empatia. Visando pensar em respostas para o futuro centramos nosso objetivo no desenvolvimento de perguntas. Isso almejando formar através da criatividade e da criticidade o respeito a diversidades socioculturais propiciando, como Jacobi (2007) anunciou, outras atitudes e comportamentos diante do consumismo excessivo e face ao estímulo da mudança de valores individuais e coletivos. Isso porque mais do que curar a humanidade de uma doença de escala global é preciso que seja sanada a necessidade de olhar para nós mesmos enquanto seres que agem e cujas ações repercutem positiva ou negativamente no mundo.

\section{REFERÊNCIAS}

BECK, U. A Reinvenção da política: rumo a uma teoria da modernização reflexiva. In: GIDDENS, A.; BECK, U.; LASH, Scott. Modernização reflexiva: política, tradição e estética na ordem social moderna. Trad. Magda Lopes. São Paulo: Editora da Unesp, 1997, p. 11-71. 
COMISSÃO MUNDIAL SOBRE MEIO AMBIENTE E DESENVOLVIMENTO (CMMAD). Nosso futuro comum. Rio de Janeiro: Fundação Getúlio Vargas, 1988.

DUARTE JÚNIOR, J. F. O sentido dos sentidos: a educação (do) sensível. Curitiba: Criar edições, 2001.

FRANCIONE, G. L. Introdução aos direitos animais. Tradução de Regina Rheda. Campinas: Editora da Unicamp, 2013 [1954].

JACOBI, P. R. Educar na sociedade de risco: o desafio de construir alternativas. Pesquisa em Educação Ambiental, v. 2, n. 2, p. 49-65, jul./dez. 2007.

KANT, I. Crítica da razão pura. Trad. Fernando Costa Mattos. Petrópolis: Vozes, 2013.

LARAIA, R. B. Cultura: um conceito antropológico. Rio de Janeiro: Jorge Zahar, 2004.

LISPECTOR, C. Laços de família. Rio de Janeiro: Rocco, 1988.

LUCENA, C. C. de; HOLANDA-FILHO, Zenildo Ferreira; BOMFIM, Aurélio Delmondes. Atuais e potenciais impactos do coronavírus (Covid-19) na caprinocultura e ovinocultura. CIM. Centro de Inteligência e Mercado de Caprinos e Ovinos, n. 10, p. 1-6, abr. 2020.
MACIEL, M. E. (Org.). Pensar/escrever o animal: ensaios de zoopoética e biopolítica. Florianópolis: Editora da UFSC, 2011.

NATIONAL GEOGRAFIC. Animais selvagens também praticam distanciamento social para evitar adoecer. 14 abr. 2020. Disponível em: <<https://www.nationalgeographicbrasil.com /animais/2020/04/animais-selvagensdistanciamento-social-doencas-coronaviruscovid-19-abelha >> Acessado em 4 de maio de 2020 .

NETTO, F. de F.. A natureza humana e suas formas de exteriorização em tempos de pandemia da covid-19. Boletim de Conjuntura (Boca), ano II, v. 2, n. 4, p. 1-6, 2020.

NUNES, J. A pandemia de COVID-19: securitização, crise neoliberal e a vulnerabilização global. Espaço Temático: COVID-19 - contribuições da saúde coletiva. Cad. Saúde Pública, v. 36, n. 4, p. 1-5, 2020.

NUNES, B. O animal e o primitivo: os Outros de nossa cultura. História, Ciências, Saúde Manguinhos, v.14, suplemento, p. 279-290, dez. 2007.

PÁDUA, J. A.; LAGO, A. O que é ecologia. São Paulo: Brasiliense, 2004.

REIGOTA, M. Meio ambiente $e$ representação social. São Paulo: Cortez, 2004.

RILKE, R. M. Elegias de Duíno. São Paulo: Globo, 1984. 
SCHOPENHAUER, A. Sobre la Voluntad en La Naturaleza. Trad. Miguel de Unamuno. Buenos Aires: Ediciones Siglo Veinte, 2005.

SCOTT, W. Education and sustainable development: challenges, responsibilities, and frames of mind. The Trumpeter, v. 18, n. 1, p. 22-34, 2002.

SINGER, P. Libertação Animal. Tradução Marly Winckler. Porto Alegre: São Paulo: Lugano, 2008.

TELESSAÚDERS-UFRGS. Qual a diferença entre distanciamento social quarentena $e$ isolamento? Porto Alegre: UFRGS, 2020. Disponível em: << https://www.ufrgs.br/telessauders/posts_coro navirus/qual-a-diferenca-de-distanciamentosocial-isolamento-e-quarentena/ > Acessado em 03 de maio de 2020.

TOSTES, A.; MELO FILHO, H. (Orgs). Quarentena: reflexões sobre a pandemia e depois. Marília: Práxis, 2020.

VENTURA, D. F. de L. et al.; Desafios da pandemia de COVID-19: por uma agenda brasileira de pesquisa em saúde global e sustentabilidade. Espaço Temático: COVID19 - contribuições da saúde coletiva. Cad. Saúde Pública, v. 36, n. 4, p. 1-4, 2020.

Submetido: 04/05/2020.

Aceito: 18/06/2020. 